\title{
Formação docente: olhares sobre os saberes e práticas docentes no espaço do Pré-Universitário Popular Povo Novo
}

\author{
La formación docente: ojos sobre los saberes y prácticas docentes en el \\ contexto del curso 'Pré-Universitário Popular Povo Novo'.
Teacher training: views on teaching knowledge and practices in the space of the popular new pre-university

Fernanda Caseira das Neves ${ }^{1}$

Vilmar Alves Pereira ${ }^{2}$

\begin{abstract}
Resumo
O presente trabalho fundamenta-se em realizar uma análise da prática docente durante as minhas ações como educadora popular no contexto do curso Pré-Universitário Popular Povo Novo. Embasadas, portanto, na proposta de uma Educação Ambiental Popular possibilitando a base epistemológica orientar as atividades educativas de extensão no contexto do Programa de Auxílio ao Ingresso nos Ensinos Técnico e Superior - (PAIETS) da Universidade Federal do Rio Grande (FURG). O acesso, assim como a permanência são grandes desafios enfrentados na vida profissional do docente, principalmente no que condizem as especificidades do curriculum do próprio curso e a articulação deste com os objetivos, os métodos de ensino, o planejamento didático e as condutas de avaliação, utilizadas durante os quatro anos de formação na Universidade, instigando a redefinição das bases formativas docentes num horizonte mais humano, crítico e transformador. Assim, procurou-se entender e valorizar os saberes e as práticas no processo de construção do diálogo entre os educandos e o sujeito histórico em seu contexto, visando à avaliação como uma prática emancipatória, onde o educando possa ser visto como o principal agente em seu processo de formação e nas construções das aprendizagens em meio de uma forte onda de políticas de desvalorização da educação. Aponto durante a pesquisa como educadora popular e graduanda do curso de Letras - Espanhol o que compreendemos sobre o processo de formação e algumas de nossas expectativas e dificuldades enfrentadas no dia a dia da sala de aula.
\end{abstract}

Palavras-Chave: PAIETS; Educação Ambiental Popular; Formação de Educadores; Curriculum; Diferentes Saberes.

\section{Resumen}

El presente trabajo se basa en un análisis de la práctica docente durante mis acciones como educadora popular en el contexto del curso 'Pré-Universitário Povo Novo'. Basado, por lo tanto, en la propuesta de una Educación Ambiental Popular posibilitando la base epistemológica orientar las actividades educativas de extensión en el contexto del 'Programa de Auxilio ao Ingresso nos Ensinos Técnico e Superior (PAIETS)' de la Universidade Federal do Rio Grande (FURG). El acceso, así como la permanencia son los grandes desafíos enfrentados en la vida profesional del docente, principalmente cuando tratamos del currículo del propio curso y la articulación de este con los objetivos, los métodos de enseñanza, el planeamiento didáctico y las conductas de evaluación, utilizadas durante los cuatro años de formación en la Universidad, instigando la redefinición de las bases

\footnotetext{
${ }^{1}$ Bolsista do Programa de Extensão Universitária - PROEXT- Educadora do Pré Universitário Popular Povo Novo. Acadêmica do Curso de Letras da Universidade Federal do Rio Grande - FURG.Fernandaneves92@ hotmail.com

${ }^{2}$ Filósofo. Mestre e Doutor em Educação, Educador Popular e Ambiental. Coordenador do Programa de Pós-Graduação em Educação Ambiental da Universidade Federal do Rio Grande (FURG); Professor e Pesquisador no Instituto de Educação e nos Programas de Educação (PPGEDU) e Educação Ambiental (PPGEA) da Universidade Federal do Rio Grande- FURG. Editor Chefe da Revista Eletrônica do Mestrado em Educação Ambiental -REMEA.Vilmar1972@gmail.com
} 
formativas docentes, en un horizonte más humano, crítico y transformador. Así intentamos valorar los saberes y las prácticas en el proceso de construcción del dialogo entre los educadores y los sujetos históricos en su contexto, visando la evaluación como una práctica emancipadora, donde el educando es visto como el principal agente en su proceso de formación y en las construcciones de las aprendizajes en medio a una fuerte onda de políticas de desvaluación de la educación. Apunto durante la pesquisa lo que comprendemos sobre el proceso de formación y algunas de nuestras expectativas y dificultades enfrentadas en el día a día de la clase.

Palabras clave: PAIETS; Educación Ambiental Popular; Formación de Educadores; Currículo; Diferentes Saberes.

\begin{abstract}
The present work is based on an analysis of my teaching practice during my actions as a popular educator in the context of the Popular People's Pre-University Course. Based, therefore, on the proposal of a Popular Environmental Education allowing the epistemological basis to guide the extension educational activities in the context of the Program of Assistance to the Entry into Technical and Higher Education - (PAIETS) of the Federal University of Rio Grande (FURG). Access, as well as permanence, are major challenges faced in the teacher's professional life, especially as they match the specificities of the curriculum of the course itself and its articulation with the objectives, teaching methods, didactic planning and assessment conducts, used during the four years of formation at the University, instigating the redefinition of the teaching formative bases in a more human, critical and transforming horizon. Thus, we sought to understand and value the knowledge and practices in the process of building dialogue between the students and the historical subject in their context, aiming at the evaluation as an emancipatory practice, where the student can be seen as the main agent in their formation process and the construction of learning in the midst of a strong wave of policies of devaluation of education. I point out during the research what we understand about the training process and some of our expectations and difficulties faced in the classroom.
\end{abstract}

Keywords: PAIETS; Popular Environmental Education; Educator training; Curriculum; Different knowledge.

\title{
1. Introdução
}

Vivenciamos um momento no Brasil, em que as camadas populares são as que mais sofrem, pois a elas são encolhidos e negados direitos cotidianamente. É caso das múltiplas reformas pós-golpe que vem limitando ao filho e filha do trabalhador (a) as possibilidades de ter acesso às garantias básicas. Em estudos anteriores, problematizamos que as práticas são reafirmadas através dos inúmeros discursos sob os efeitos das políticas neoliberais, que estão enraizadas em todos os campos, inclusive os da educação como veem em uma ocasião de formação de professores:

\footnotetext{
¿Quién soy yo en mi docencia? ¿Un facilitador o un problematizador? ¿Existe diferencia entre facilitar y problematizar? Y no que se refiere a las constantes invitaciones: ¿Qué significa educar para emprender? ¿De dónde viene esa matriz emprendedora? Otra cuestión: "tenemos que educar para el mercado de trabajo". Pregunto: ¿Existe diferencias entre educar para el mercado de trabajo o educar para

${ }^{1}$ Bolsista do Programa de Extensão Universitária - PROEXT- Educadora do Pré Universitário Popular Povo Novo. Acadêmica do Curso de Letras da Universidade Federal do Rio Grande - FURG. Fernandaneves92@hotmail.com

${ }^{2}$ Filósofo. Mestre e Doutor em Educação, Educador Popular e Ambiental. Coordenador do Programa de Pós-Graduação em Educação Ambiental da Universidade Federal do Rio Grande (FURG); Professor e Pesquisador no Instituto de Educação e nos Programas de Educação (PPGEDU) e Educação Ambiental (PPGEA) da Universidade Federal do Rio Grande- FURG. Editor Chefe da Revista Eletrônica do Mestrado em Educação Ambiental -REMEA.Vilmar1972@gmail.com
} 
el mundo del trabajo? Lo mismo puede ocurrir en relación, por ejemplo, al desarrollo sostenible. ¿Qué sostenibilidad es esa? ¿Económica o socio ambiental? Y la innovación ¿Qué significa? Innovar para cambiar apenas la forma, innovar para emprender financieramente o innovar para la creatividad. Y el debate tan acogido en América Latina sobre educar por competencia y habilidades apuntando la excelencia. ¿Quién ambiciona ese sujeto competente? ¿Qué mercado es ese para ese sujeto hábil? ¿Qué habilidades es esa? ¿Qué discurso de excelencia es ese? ¿Meritocrático? (PEREIRA, 2017, p.3)

É diante a esse cenário de incertezas e de diminuição de direitos que necessitamos de projetos e ações coletivas voltadas para a luta e defesa de nossas garantias, sendo uma delas o acesso à educação pública e de qualidade. É nesse âmbito que passamos a apresentar o Programa de Auxílio ao Ingresso nos Ensinos Técnico e Superior - PAIETS e a relação de troca de saberes que há entre o curriculum do curso de Letras e a Educação Ambiental Popular, objetivando apresentar uma análise de como e quando a questão dos saberes docentes aparecem nas investigações sobre formação de professores.

\section{Contextualizando o Programa de Auxílio ao Ingresso nos Ensinos Técnico e Superior - PAIETS}

Trata-se de um Programa de inclusão social e de ações afirmativas que atua em três instancias: 1. Auxilio ao Ingresso no Ensino Superior e Técnico; 2. Permanência das Camadas populares e comunidades tradicionais (indígenas e quilombolas) na Universidade; e 3. Retomada ao acesso da Educação Básica nas comunidades tradicionais de pesca artesanal. Desse modo, o Programa agrupa 10 Cursos Pré-Universitários Populares voltados ao ingresso nos ensinos superior e técnico, configurando-se enquanto um movimento articulador entre as comunidades urbanas periféricas por meio da busca ao direito do ingresso das camadas populares nos espaços educativos historicamente destinados às camadas mais abastadas.

As práticas educativas (aulas) englobam o conteúdo das disciplinas requeridas nos processos seletivos de maneira expositivo-dialógica, de forma que os educandos se tornem sujeitos de seu processo de aprendizagem. As demais atividades - ações de extensão interdisciplinar - articulam o apoio psicológico, de formação e capacitação dos educadores sob a perspectiva da cidadania, da educação ambiental e dos direitos humanos.

\footnotetext{
${ }^{1}$ Bolsista do Programa de Extensão Universitária - PROEXT- Educadora do Pré Universitário Popular Povo Novo. Acadêmica do Curso de Letras da Universidade Federal do Rio Grande-FURG.Fernandaneves92@hotmail.com

${ }^{2}$ Filósofo. Mestre e Doutor em Educação, Educador Popular e Ambiental. Coordenador do Programa de Pós-Graduação em Educação Ambiental da Universidade Federal do Rio Grande (FURG); Professor e Pesquisador no Instituto de Educação e nos Programas de Educação (PPGEDU) e Educação Ambiental (PPGEA) da Universidade Federal do Rio Grande- FURG. Editor Chefe da Revista Eletrônica do Mestrado em Educação Ambiental -REMEA.Vilmar1972@gmail.com
} 
Com efeito, o Programa realiza espaços dialógicos nas áreas de conhecimento e apresentando tais possibilidades aos sujeitos que buscam ingressar no Ensino Superior. Mas para além do ingresso nas universidades e cursos técnicos, o PAIETS enquanto instituição busca principalmente promover a formação crítica dos sujeitos a partir de sua leitura de mundo.

Para Freire, a experiência a partir da leitura de mundo demonstra, sobretudo, os caminhos do aprendizado da leitura para além da palavra: os sujeitos em processo educativo buscavam (re) conhecer seu espaço e sua "realidade". Trata-se da "leitura de mundo", categoria está tão cara à concepção de Educação Popular. Cumpre salientar: "A leitura do mundo precede a leitura da palavra, daí que a posterior leitura desta não possa prescindir da continuidade da leitura daquele. Linguagem e realidade se prendem dinamicamente" (FREIRE, 2001, p.11).

Atualmente, atuo no Programa como secretária e educadora popular no contexto do Pré-Universitário Povo Novo, $3^{\circ}$ distrito de Rio Grande, no qual resido. O curso préuniversitário emergiu em 2017, contanto com a participação de 10 educadores populares graduandos, graduados e pós-graduados. Tínhamos um panorama traçado entre o agravamento na qualidade do ensino público e a falta de acesso as Universidades, onde muitos sujeitos, se não a sua maioria, sequer concluíam o ensino médio. Ingressar na Universidade então, se apresentava como uma verdadeira utopia para muitos.

Diante dessas condições, inspirados em Paulo Freire e em sua Pedagogia da Esperança (1992) acreditamos, na necessidade da esperança e do sonho para a existência humana como aspecto elementar da atividade cidadã enquanto educadores: "uma das tarefas do educador ou educadora é desvelar as possibilidades para a esperança, não importam os obstáculos (...) sem poder negar a desesperança como algo concreto e sem desconhecer as razões históricas, econômicas e sociais que a explicam, não podemos prescindir da esperança na luta por um mundo melhor".

\section{A Educação brasileira}

Decorrente da realidade brasileira, a busca por novas perspectivas e paradigmas relativos ao conteúdo escolar se dá a partir da década de 1990, onde se passou a destacar a importância de se pensar a formação numa abordagem que vá além da academia, envolvendo

\footnotetext{
${ }^{1}$ Bolsista do Programa de Extensão Universitária - PROEXT- Educadora do Pré Universitário Popular Povo Novo. Acadêmica do Curso de Letras da Universidade Federal do Rio Grande - FURG. Fernandaneves92@ hotmail.com

${ }^{2}$ Filósofo. Mestre e Doutor em Educação, Educador Popular e Ambiental. Coordenador do Programa de Pós-Graduação em Educação Ambiental da Universidade Federal do Rio Grande (FURG); Professor e Pesquisador no Instituto de Educação e nos Programas de Educação (PPGEDU) e Educação Ambiental (PPGEA) da Universidade Federal do Rio Grande- FURG. Editor Chefe da Revista Eletrônica do Mestrado em Educação Ambiental -REMEA. Vilmar1972@gmail.com
} 
o desenvolvimento pessoal da profissão docente. Percebe-se neste momento uma "virada" nos estudos que cada vez mais valorizam os saberes construídos pelos professores. Nesse espírito, tinha-se em vista que, "era preciso investir positivamente os saberes de que o professor é portador, trabalhando-os de um ponto de vista teórico e conceptual.” (Nóvoa, 1992, p 27).

Repensando a formação dos professores a partir da análise da prática pedagógica, Pimenta (1999) identifica o aparecimento da questão dos saberes como um dos aspectos considerados nos estudos sobre a identidade da profissão do professor. Parte da premissa de que essa identidade é construída a partir da:

Significação social da profissão; da revisão constante dos significados sociais da profissão; da revisão das tradições. Mas também da reafirmação das práticas consagradas culturalmente e que permanecem significativas. Práticas que resistem a inovações porque prenhes de saberes valido ás necessidades da realidade. Do conforto entre as teorias e as práticas, da análise sistemática das práticas, à luz das teorias existentes, da construção de novas teorias. (p.19).

Atribuído as discussões sobre os saberes docentes e a formação de professores está à discussão sobre temas como o processo ensino-aprendizagem e a relação teoria-prática no cotidiano escolar. Tínhamos um quadro em que a escola era vista como um local privilegiado/centralizado, e o professor como o ser único que detinha o conhecimento, o poder e a sabedoria exercendo apenas um papel - transmissor de saberes.

Com o passar dos anos, percebe-se uma nova fundamentação do trabalho do professor, este que passa a ser visto como um profissional, ou seja, como aquele que, a partir dos seus conhecimentos previamente estabelecidos está apto a deliberar, julgar e decidir com relação às ações a serem adotadas, a palavra pronunciada, antes, durante e após o ato pedagógico, exercendo seu papel de mediador por meio da discussão de suas experiências de vida, através da fundamentação humanista.

A fim de repensar a formação inicial e continuada a partir da análise e das práticas pedagógicas, Pimenta (1999) desenvolve uma pesquisa a partir de sua prática com alunos de licenciatura e destaca a importância da mobilização dos saberes da experiência para a construção da identidade profissional do professor. Neste sentido são identificados três tipos de saberes da docência:

a) da experiência, que seria aquele aprendido pelo professor desde quando aluno, com os professores significativos assim, como num processo de reflexão e troca

\footnotetext{
${ }^{1}$ Bolsista do Programa de Extensão Universitária - PROEXT- Educadora do Pré Universitário Popular Povo Novo. Acadêmica do Curso de Letras da Universidade Federal do Rio Grande-FURG.Fernandaneves92@hotmail.com

${ }^{2}$ Filósofo. Mestre e Doutor em Educação, Educador Popular e Ambiental. Coordenador do Programa de Pós-Graduação em Educação Ambiental da Universidade Federal do Rio Grande (FURG); Professor e Pesquisador no Instituto de Educação e nos Programas de Educação (PPGEDU) e Educação Ambiental (PPGEA) da Universidade Federal do Rio Grande- FURG. Editor Chefe da Revista Eletrônica do Mestrado em Educação Ambiental -REMEA.Vilmar1972@gmail.com
} 
com os colegas; b) do conhecimento, que abrange a revisão da função da escola na transmissão dos conhecimentos e as suas especialidades num contexto contemporâneo e c) dos saberes pedagógicos, aquele que abrange a questão do conhecimento juntamente com o saber da experiência e dos conteúdos específicos e que será construído a partir das necessidades pedagógicas reais.

\section{Relação entre prática e teoria}

Identificamos os saberes docentes como constituídos pelos educadores através de uma prática reflexiva e investigativa. As relações pré-estabelecidas em cada grupo, sejam eles social, profissional ou familiares fará a articulação da teoria com a prática contribuindo na formação do professor de forma contínua e coletiva. Segundo Haberman:

$\mathrm{O}$ interesse técnico instrumental, em que se utilizam explicações cientifica e objetivos, baseado no modelo da racionalidade técnica; e o interesse prático, que efetiva a interpretação dos significados produzidos pelos praticantes do mundo-vida como subsídio para emissão de um juízo prático. Haveria ainda um terceiro que seria o interesse emancipatório. Aquele que "exige que se ultrapassem quaisquer interpretações estreitas e acríticas para com os significados subjetivos, a fim de alcançar um conhecimento emancipador que permite avaliar as condições/determinações sociais, culturais e políticas em que se produzem a comunicação e a ação social” (p.315).

Percebo assim, que à medida que o professor articula o conhecimento teóricoacadêmico à cultura escolar e a reflexão sobre sua prática docente através das práxis educativas, desenvolver a partir desta perspectiva uma "epistemologia da prática" que explica como se configura o processo de aprender e ensinar, procurando identificar quais conhecimentos são desenvolvidos pelo professor ao atuar. O grande desafio é, portanto, saber onde buscar algo que não existe, uma nova forma de ensinar respeitando tudo o que foi vivido, construindo uma concepção adequada á realidade dos contextos escolares, respeitando as peculiaridades de cada comunidade e seus sujeitos.

Nesta situação percebemos a dificuldade do professor iniciante em pôr em prática os conhecimentos teóricos recebidos na academia. Temos o conhecimento teórico, no entanto, não sabemos como adaptá-lo a cada contexto. Como experiência, já a dois anos no préuniversitário, procuro desenvolver dinâmicas a partir de inquietações dos próprios educandos e assimilá-las ao conteúdo "programático" do Exame Nacional do Ensino Médio - ENEM.

\footnotetext{
${ }^{1}$ Bolsista do Programa de Extensão Universitária - PROEXT- Educadora do Pré Universitário Popular Povo Novo. Acadêmica do Curso de Letras da Universidade Federal do Rio Grande - FURG. Fernandaneves92@ hotmail.com

${ }^{2}$ Filósofo. Mestre e Doutor em Educação, Educador Popular e Ambiental. Coordenador do Programa de Pós-Graduação em Educação Ambiental da Universidade Federal do Rio Grande (FURG); Professor e Pesquisador no Instituto de Educação e nos Programas de Educação (PPGEDU) e Educação Ambiental (PPGEA) da Universidade Federal do Rio Grande- FURG. Editor Chefe da Revista Eletrônica do Mestrado em Educação Ambiental -REMEA. Vilmar1972@gmail.com
} 
No entanto, este não é o único objetivo, quando desenvolvo um plano de aula adequado a cada turma e a cada indivíduo presente, reflito em como a partir desta minha aula e sendo ética com o conhecimento que adquiri ao longo da minha formação, possa contribuir para que ao final de cada jornada esses educandos saiam sujeitos mais críticos, formadores de ideias e conceitos que irão contribuir não somente consigo, como também com a sua comunidade.

\section{A formação social}

Como havia citado anteriormente, a pesquisa emergiu a partir da experiência na prática pedagógica realizada no contexto do Pré-Universitário Povo Novo. Assim, pensar em nossa formação requer capacitação e preparo para encararmos os desafios exprimidos no âmbito escolar estreitando os vínculos entre teoria e prática, educador e educando, sujeito e comunidade.

Dejair Dionísio (2000) a partir do pensamento de Norbert Elias traça uma ideia do que pensamos ser a educação permeada na sociedade. $\mathrm{O}$ pesquisador alerta que tanto a sociedade como o indivíduo não podem ser pensados de formas distintas, pois tanto um quanto o outro, se formam e são únicos em si mesmo Elias (1997) ainda afirmará que as pessoas, de forma geral, estarão propensas a se ver como civilizadas, em relação aos seus congêneres anteriores, acreditando que o seu processo e padrão de civilização e racionalidade estariam para além da barbárie das sociedades passadas.

Nesse sentido, Freire (1992) coloca que o educador deve instigar os seus alunos a defender aquilo que lhes parece certo: "Que educador seria eu se não me sentisse movido por forte impulso que me faz buscar, sem mentir, argumentos convincentes na defesa dos sonhos porque luto? Na defesa da razão de ser da esperança com que atuo como educador". Na perspectiva pedagógica freireana, o conhecimento está a serviço da transformação da realidade social e da ampliação do acesso dos bens produzidos pela e para a sociedade. Assim, pautamo-nos enquanto educadores pela mobilização cidadã dos acadêmicos junto às comunidades e também na auto-organização dos cursos preparatórios populares como espaços de realização destas esperanças.

\section{Desafios da formação docente}

"Todo ato pedagógico não ocorre sozinho e, portanto, constitui-se em um ato político que possuiu uma teoria que fundamenta minha forma de ser professor e educador". PEREIRA,2019.

\footnotetext{
${ }^{1}$ Bolsista do Programa de Extensão Universitária - PROEXT- Educadora do Pré Universitário Popular Povo Novo. Acadêmica do Curso de Letras da Universidade Federal do Rio Grande - FURG. Fernandaneves92@ hotmail.com

${ }^{2}$ Filósofo. Mestre e Doutor em Educação, Educador Popular e Ambiental. Coordenador do Programa de Pós-Graduação em Educação Ambiental da Universidade Federal do Rio Grande (FURG); Professor e Pesquisador no Instituto de Educação e nos Programas de Educação (PPGEDU) e Educação Ambiental (PPGEA) da Universidade Federal do Rio Grande- FURG. Editor Chefe da Revista Eletrônica do Mestrado em Educação Ambiental -REMEA.Vilmar1972@gmail.com
} 
A partir da perspectiva e dos princípios da Educação Popular Ambiental buscamos no conjunto de nossas ações sempre partir dos reconhecimentos dos saberes dos diferentes sujeitos respeitando os saberes docentes por este recebido durante sua formação, enfatizando que o saber é constituído a partir do contexto histórico e social vivenciado e transformado em saber da experiência.

Um dos principais desafios enquanto educadora emergiu da concepção de que não existe neutralidade no ato educativo, no qual o ser humano constitui-se na e como historicidade "o saber da história como possibilidade e não como determinação" (FREIRE, 1996, p.85). Formar sujeitos críticos requer um movimento com intencionalidades claras de promover trocas em nossa forma de ser, de pensar e viver a educação, atitude de sujeito que transforma o meio em que vive de forma consciente e responsável.

Deste modo, acredita-se que durante a graduação tendemos a nos direcionarmos a metodologias que melhor nos representam, refletindo ao longo de nossa constituição sobre quem sou eu em minha docência? Um educador facilitador, mediador ou problematizador? Subentende-se - nas bases epistemológicas de Pedagogia do oprimido, reafirmado em Pedagogia da esperança, - que a grande mediação pedagógica dos oprimidos se processa pelo engajamento na luta política realizada de forma solidária, "educando-se entre si, mediatizados pelo mundo" (FREIRE, 1978, p.63), onde o (a) educador (a) pode oferecer a mediação através da problematização.

O educador (a) ao preocupar-se com a mediação pedagógica através da problematização como sinônimo da "educação libertadora" promove a humanização e a produção do pensar autêntico desenvolvendo no sujeito uma consciência crítica sobre os temas em debate pela identificação de situações desafiadoras ou de problemas concretos que envolvam a vida dos educandos. Vejo assim, a importância de um planejamento que ouça seus alunos e busque fazer interfaces significativas com o conteúdo e o contexto com o qual comunicará cada conhecimento. Segundo Libâneo (1994) “o que o professor tem a fazer é colocar o aluno em condições propícias para que, partindo das suas necessidades e estimulando os seus interesses, possa buscar por si mesmo conhecimentos e experiências" (LIBÂNEO, 1994, p. 65).

Desta forma, procuramos trabalhar no contexto do pré-universitário diferentes temas sociais, políticos e econômicos com um viés epistemológico de base interacionista e

\footnotetext{
${ }^{1}$ Bolsista do Programa de Extensão Universitária - PROEXT- Educadora do Pré Universitário Popular Povo Novo. Acadêmica do Curso de Letras da Universidade Federal do Rio Grande - FURG. Fernandaneves92@hotmail.com

${ }^{2}$ Filósofo. Mestre e Doutor em Educação, Educador Popular e Ambiental. Coordenador do Programa de Pós-Graduação em Educação Ambiental da Universidade Federal do Rio Grande (FURG); Professor e Pesquisador no Instituto de Educação e nos Programas de Educação (PPGEDU) e Educação Ambiental (PPGEA) da Universidade Federal do Rio Grande- FURG. Editor Chefe da Revista Eletrônica do Mestrado em Educação Ambiental -REMEA.Vilmar1972@gmail.com
} 
construtivista, segundo a qual o conhecimento resulta de construções do sujeito em interação com o mundo. Tentamos mostrar a eles que o espaço da sala de aula também é um espaço deles, onde eles têm o direito de falar e mais do que isso, de serem ouvidos.

A formação do educador não é, somente, construída por acumulo de cursos, de técnicas e de conhecimentos, mas sim, através de um trabalho de reflexão crítica sobre as suas práticas e de (re) construção permanente da identidade. A troca de experiências e a partilha de saberes consolidam espaços de formação.

Penso que a maior dificuldade quando falamos em formação de professores é não confundir "formar" com "formar-se", ou seja, nem sempre o contexto de atividade educativa coincidi com as dinâmicas próprias da formação. E, estar em formação implica um investimento pessoal com vista à construção de uma identidade, que é também uma identidade profissional.

\section{Considerações finais}

Percebemos que a investigação dessa temática tem possibilitado a pesquisa relacionada aos saberes e à formação de professores, desenvolvido com características próprias. De certa forma, o (re) pensar a concepção da formação dos professores requer analisar a prática considerando os diversos contextos do trabalho cotidiano, seja através da ação ou da pesquisa que constituam as trajetórias da carreira no meio universitário, mas que sejam uteis para os educadores em sua prática na busca de uma ruptura da lógica disciplinar da universidade, minimizando o abismo entre as " teorias professadas" e as "teorias praticadas".

Um dos espaços privilegiados para se pensar a própria formação, ainda enquanto um espaço de laboratório é o estágio obrigatório desenvolvido no interior da universidade que tem por objetivo unificar a teoria com a prática. Esse estágio busca, de diversas formas, demonstrar para o estudante a importância da pesquisa durante a sua vida docente.

Se conseguirmos fazer com que os educandos por meio dos conteúdos trabalhados, consigam perceber a sua realidade por meio de uma análise mais crítica passando a fazer sentido na vida deles, proporcionando não o acúmulo de conteúdo, mas, sempre por meio deles, propiciar novos olhares para pensar o real sentido crítico.

Nessa perspectiva, não visamos apenas transmitir os conhecimentos e/ou conteúdos do ENEM junto aos educandos. Ao trabalhar os mesmos, e contribuir para sua qualificação e

\footnotetext{
${ }^{1}$ Bolsista do Programa de Extensão Universitária - PROEXT- Educadora do Pré Universitário Popular Povo Novo. Acadêmica do Curso de Letras da Universidade Federal do Rio Grande - FURG. Fernandaneves92@hotmail.com

${ }^{2}$ Filósofo. Mestre e Doutor em Educação, Educador Popular e Ambiental. Coordenador do Programa de Pós-Graduação em Educação Ambiental da Universidade Federal do Rio Grande (FURG); Professor e Pesquisador no Instituto de Educação e nos Programas de Educação (PPGEDU) e Educação Ambiental (PPGEA) da Universidade Federal do Rio Grande- FURG. Editor Chefe da Revista Eletrônica do Mestrado em Educação Ambiental -REMEA. Vilmar1972@gmail.com
} 
preparação aos processos seletivos, buscamos ainda produzir cidadania, participação crítica e envolvimento de todos/das na melhoria das condições materiais de estudo. Também entendemos que os conhecimentos trabalhados e construídos nestes processos, não estão dissociados da realidade e das ações de cada um na sua efetivação.

Assim, esperamos contribuir para que os educandos engajados sejam agentes e cidadãos de suas vidas, além de obterem a tão esperada aprovação nos processos seletivos em que estão envolvidos e/ou estão se preparando. Enfim, buscamos a nossa própria transformação em cidadãos mais críticos como educadores, mas também, no desenvolvimento das ações e das atividades educativas envolvendo nossos educandos e as comunidades respectivamente.

\section{Referências}

BORGES, C.M.F. Formação e prática pedagógica do professor de educação física: A construção do saber docente. In: Anais da 19ª Anped, 1996 (disq.).

ELIAS, Norbert. Norbert Elias por ele mesmo. Rio de Janeiro: Zahar, 2001 ${ }^{\mathrm{a}}$.

LIBÂNEO, José Carlos. Didática. - São Paulo: Cortez, 1994 (Coleção magistério $2^{\circ}$ grau. Série formação do professor)

NÓVOA, A. (Org.). Vidas de Professores. Porto Editora, 1992.

NÓVOA, A. Os professores e as histórias da sua vida. In: (Org.). Vidas de professores. Porto Editora, 1995.

PEREIRA, Vilmar Alves. Situación y desafíos de la formación y capacitación de docentes. Revista Signos, Lajeado, 2017.

PIMENTA, S.G. Formação de professores: Identidade e saberes da docência. In: PIMENTA, S.G. (Org.). Saberes pedagógicos e atividade docente. São Paulo: Cortez, 1999.

\footnotetext{
${ }^{1}$ Bolsista do Programa de Extensão Universitária - PROEXT- Educadora do Pré Universitário Popular Povo Novo. Acadêmica do Curso de Letras da Universidade Federal do Rio Grande - FURG. Fernandaneves92@hotmail.com

${ }^{2}$ Filósofo. Mestre e Doutor em Educação, Educador Popular e Ambiental. Coordenador do Programa de Pós-Graduação em Educação Ambiental da Universidade Federal do Rio Grande (FURG); Professor e Pesquisador no Instituto de Educação e nos Programas de Educação (PPGEDU) e Educação Ambiental (PPGEA) da Universidade Federal do Rio Grande- FURG. Editor Chefe da Revista Eletrônica do Mestrado em Educação Ambiental -REMEA. Vilmar1972@gmail.com
} 
TOLEDO, Rogéria Viol Ferreira. O papel das licenciaturas na constituição dos saberes docentes: um estudo sobre a formação inicial do professore de matemática à luz da prática escolar. Viçosa, Minas Gerais, 2013.

BENTO, F. R. Conexões entre Marxismo e religião. RELACult - Revista Latino-Americana de Estudos em Cultura e Sociedade, [S.1.], v. 2, n. 02, p. 07-25, out. 2016. ISSN 2525-7870. Disponível em: http://periodicos.claec.org/index.php/relacult/article/view/6. Acesso em: 31 dez. 2016. (Artigo em Periódico Digital)

OLIVEIRA, D. G. A mediação pedagógica como prática docente: uma análise da pedagogia histórico-crítica e demais correntes pedagógicas. Revista Eletrônica: LENPES-PIBID de Ciências Sociais - UEL. Edição No. 2, Vol. 1, jul-dez. 2012. ISSN 2317-9961 Disponível em: http://www.uel.br/revistas/lenpespibid/pages/arquivos/2\%20Edicao/DIEGO\%20\%20para\%20publicar\%20revista\%20lenpes.pd f. Acesso em 25 agosto 2019.

DIONÍSIO, Dejair. Educação e Sociedade. 2016. Disponível em http://repositorio.unicentro.br:8080/jspui/bitstream/123456789/505/5/Educa\%C3\%A7\%C3\% A3o\%20e\%20Sociedade.pdf . Acesso em 20 agosto 2019.

NÓVOA, Antonio. Formação de professores e profissão docente. 1992. Disponível em: https://core.ac.uk/download/pdf/12424596.pdf . Acesso em 15 agosto 2019.

Toledo, R Viol Ferreira. O papel das licenciaturas na constituição dos saberes docentes: um estudo sobre a formação inicial do professor de matemática à luz da prática escolar. Disponível em https://www.locus.ufv.br/handle/123456789/3446 . Acesso em 10 agosto 2019.

Portal do Centro Latino-Americano de Estudos em Cultura (CLAEC). Disponível em: http://www.claec.org. Acesso em: 26 julho 2015. (Modelo para Sites).

NUNES, CÉLIA MARIA FERNANDES. Saberes docentes e formação de professores: um breve panorama da pesquisa brasileira. Educ. Soc. [online]. 2001, vol.22, n.74, pp.27-

\footnotetext{
${ }^{1}$ Bolsista do Programa de Extensão Universitária - PROEXT- Educadora do Pré Universitário Popular Povo Novo. Acadêmica do Curso de Letras da Universidade Federal do Rio Grande-FURG. Fernandaneves92@hotmail.com

${ }^{2}$ Filósofo. Mestre e Doutor em Educação, Educador Popular e Ambiental. Coordenador do Programa de Pós-Graduação em Educação Ambiental da Universidade Federal do Rio Grande (FURG); Professor e Pesquisador no Instituto de Educação e nos Programas de Educação (PPGEDU) e Educação Ambiental (PPGEA) da Universidade Federal do Rio Grande- FURG. Editor Chefe da Revista Eletrônica do Mestrado em Educação Ambiental -REMEA. Vilmar1972@gmail.com
} 
42. Disponível em: https://www.scielo.br/scielo.php?pid=S0101-

$73302001000100003 \&$ script=sci_abstract\&tlng=pt Acesso em 31 de agosto de 2019.

\footnotetext{
${ }^{1}$ Bolsista do Programa de Extensão Universitária - PROEXT- Educadora do Pré Universitário Popular Povo Novo. Acadêmica do Curso de Letras da Universidade Federal do Rio Grande - FURG. Fernandaneves92@hotmail.com

${ }^{2}$ Filósofo. Mestre e Doutor em Educação, Educador Popular e Ambiental. Coordenador do Programa de Pós-Graduação em Educação Ambiental da Universidade Federal do Rio Grande (FURG); Professor e Pesquisador no Instituto de Educação e nos Programas de Educação (PPGEDU) e Educação Ambiental (PPGEA) da Universidade Federal do Rio Grande- FURG. Editor Chefe da Revista Eletrônica do Mestrado em Educação Ambiental -REMEA.Vilmar1972@gmail.com
} 